\title{
Psychological Burden and Medication Adherence of Human Immunodeficiency Virus Positive Patients
}

\author{
Yunhee Park ${ }^{1}$ \\ ${ }^{1}$ Department of Nursing, College of Medicine, Wonkwang University, South Korea \\ Correspondence: Yunhee Park, Department of Nursing, College of Medicine, Wonkwang University, 460, \\ Iksandae-ro, Iksan, Jeonbuk, 54538, South Korea. Tel: 82-63-850-6028, E-mail: yhpark118@wku.ac.kr
}

Received: September 4, 2018 Accepted: September 20, 2018 Online Published: October 13, 2018

doi:10.5539/gjhs.v10n11p124 URL: https://doi.org/10.5539/gjhs.v10n11p124

\begin{abstract}
Background: Highly active antiretroviral therapy (HAART), which is a combination therapy that uses antiretroviral drugs, represents the only available therapy for combating the human immunodeficiency virus (HIV) infection. For Korean patients with HIV, it is difficult to maintain an optimal medication. The HIV- positive Korean patients that suffer from psychological burdens have low levels of medication adherence, which can lead to an increased mortality rate and a deteriorated quality of life.
\end{abstract}

Aim: The purpose of this study was to investigate the level of medication adherence of Korean patients with HIV, and to identify the pathway through which the psychological burden impact medication adherence.

Methods: With a sample of 265 HIV-positive patients, the direct and indirect effects of the psychological burden on treatment adherence were estimated with structural equation modeling.

Results: The variable that had a significant direct effect on medication adherence was self-management $(\beta=.31, p$ $=.002)$. Psychological burden was found to have a significant impact on medication adherence mediated by self-management $(\beta=-.15, p=.002)$.

Conclusion: These results revealed that continuous monitoring of patients' psychological burdens, as well as the development and application of intervention programs focused on psychological support and self-management, are necessary to improve medication adherence.

Keywords: Human immunodeficiency virus (HIV), antiretroviral, adherence, anxiety, depression

\section{Introduction}

\subsection{Backgrounds}

With recent introduction of antiretroviral (ARV) drugs, the perception about HIV has shifted from that of a fatal disease to instead a chronic disease. Highly active antiretroviral therapy (HAART), which is a combination therapy that utilizes ARV drugs, represents the only choice for HIV infections as it delays the progression of HIV to AIDS and thereby improves survival rates by maintaining the patient's immunity (Mills \& Ford, 2012). However, the ideal medication adherence for optimal viral suppression is a very high $95 \%$, and this $95 \%$ adherence late must be maintained lifelong (Lima et al., 2008). Maintaining such a high medication adherence rate is difficult Korean HIV patients (Park, Seo, Kim, \& Park, 2014). Not meeting such medication adherence level causes a drastic decrease in the number of CD4+ cells and an increase in the number of HIV, which can lead to a rapid increase in drug resistance and ultimately to treatment failure or death because of the resulting limited available number of drug therapies (Parker et al., 2017).

The psychological burden caused by HIV infection is known to have a negative effect on the patient complying with long-term treatments like HAART (Gonzalez, Batchelder, Psaros, \& Safren, 2011). HIV-positive patients typically suffer from psychological problems, such as depression or anxiety (Nanni, Caruso, Mitchell, Meggiolaro, \& Grassi, 2015). It is also common to find patients who show extreme behaviors, like suicide attempts, due to the recurring depressive symptoms or the severe anxiety symptoms that arise from being unable to focus on treatment (Park et al., 2014). In addition, HIV-positive patients often experience additional psychological problems, such as facing a negative stigma, discrimination, and isolation, all of which further exacerbate their depression and anxiety (Nanni, et al., 2015). The exacerbation of the patients' depression and/or anxiety causes lower HAART medication 
adherence and can subsequently lead to an increased mortality rate (Gonzalez et al., 2011).

In fact, many HIV-positive patients give up on HAART due to the psycho-social challenges that they must overcome in their daily lives (Murray et al., 2009). Among these patients who do give up, about $41 \%$ consequently die from HIV/AIDS (Dalal et al., 2008). In particular, if the opportunity for early treatment is lost due to the psychological burden, the probability of achieving a successful treatment outcome is reduced; this lack of early treatment also reduce the likelihood of gaining personal or public health benefits, like preventing the spread of the virus (Cohen et al., 2011). Based on these potentially serious consequences, psycho-social support is recognized as a key element in comprehensive HIV care; consequently, there are numerous intervention programs developed that focus on psycho-social factors for the purpose of improving HIV-positive patients' quality of life and medication adherence (van Luenen, Garnefski, Spinhoven, Spaan, Dusseldorp, \& Kraaij, 2018). However, despite the fact that the psychological burden of HIV infection is an issue generally faced by HIV-positive patients, there is a lack of research that explore the direct and indirect effects on medication adherence. To improve effectiveness of health promotion program focus on medication adherence of HIV-positive patients we need a better understanding of the nature of these relationships (Schönnesson, Williams, Ross, Bratt, \& Keel, 2007).

Aside from the psychological burden, a wide variety of individual and environmental factors influence adherence to HAART, which generally include demographic, clinical, socioeconomic, and health behavior-related factors (Gari, Doig-Acuna, Smail, Malungo, Martin-Hilber, \& Merten, 2013). When explaining a health promoting behavior like medication adherence, an assuming that the effects of psychological burdens have a singular relationship with medication adherence limits the ability to provide a complete, well-rounded explanation for the behaviors of HIV-positive patients.

Based on this need to provide a complete explanation, the present study examines the effects that the psychological burden has on medication adherence in Korean patients with HIV. To perform a comprehensive consideration of the multi-dimensional factors that influence psychological burdens, this study uses a structural equation model that simultaneously estimates the direct and indirect effects of these variables. With this model, this research will hopefully provide an enhanced explanation for what causes treatment adherence, which can subsequently be used to propose a framework for the development of an effective intervention program to increase medication adherence of HIV-positive patients.

\subsection{Conceptual Framework and Hypothetical Model}

Based on previous studies, the present study used latent variables, comprised of the psychological burden, socioeconomic factors, clinical factors, and health behavioral factors, for the conceptual framework and in the hypothetical model based on the assumption that these factors will have an effect on medication adherence (Tran, Nguyen, Nguyen, Hoang, \& Hwang, 2013; Wasti, Stmkhada, Randall, Freeman, \& van Teijingen, 2012; Gay et al., 2011, Malow et al., 2013). Moreover, as a conceptual framework, this study analyzed the relationships between the multiple factors and established various paths where the factors likely provided influence. For example, this research described paths wherein the socioeconomic factors were considered as predisposing influences on thepsychological burden and the clinical and health behavioral factors (Gibson, Neita, Abel, James, \& Eldemire-Shearer, 2013). Also, clinical factors were considered to have a direct effect on the psychological burden and the health behavioral factors, while the psychological burden was considered to have a direct effect on the health behavioral factors (Kabore et al., 2010). This conceptual framework is shown in Figure 1.

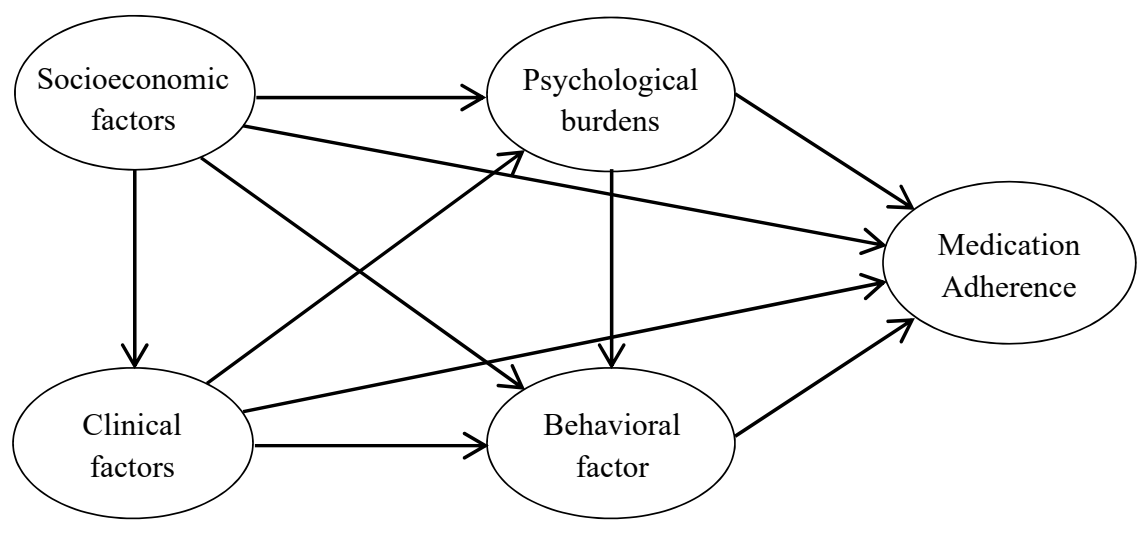

Figure1. Hypothetical model of this study 


\section{Methods}

\subsection{Study Design}

The present study used a structural equation model for identifying the direct and indirect effects of the psychological burden on medication adherence among Korean HIV-positive patients.

\subsection{Participants}

The convenience sample of this study was comprised of 265 HIV-positive patients who had previously visited the division of infectious diseases at Y University hospital in Seoul, South Korea. The inclusion criteria were the following: 1) patients with HIV aged 20 years or older; 2) patients undergoing HAART at the time of study; and 3) patients who had been diagnosed with HIV for over a year and who have experience with disease-related self-management. However, those who were actively participating in any other HIV-related intervention programs were excluded. In order for the structural equation model to be acceptable, the amount of information provided by the measured variables had to be equal to or greater than the estimated number of unknowns. The model is considered to be parsimonious when these prerequisites of the model have been satisfied. The model used in the present study contained 12 measured variables; subsequently, the amount of information obtained by this model was 78 , which was based on the formula "measurement variable $\times($ measurement variables +1$) / 2$." The number of unknowns in the saturated model was 33; therefore, this structural equation model satisfied the required conditions necessary for a parsimonious model. Moreover, the adequate sample size was calculated using the SPSS SYNTAX program with the RMSEA-based method (Kim, 2005), and the sample size required was determined to be 258.05. Considering that, the present study had a sample size of 265 , in the final analysis, the adequacy of sample size was satisfied.

\subsection{Study Instruments}

To test the validity of the study instruments used, a confirmatory factor analysis (CFA) was conducted. Consequently, the instruments with a factor loading of $\geq 0.5$ were selected. To test the model fit in CFA, optimal levels were set to normed $\chi^{2} \leq 3$, goodness of fit index (GFI) $\geq .90$, root mean squared error of approximation (RMSEA) $\leq .08$, normed fit index (NFI) $\geq .90$, Tucker-Lewis index (TLI), comparative fit index (CFI) $\geq .90$, while normed $\chi^{2}<5$, RMSEA $\leq .10$, and GFI, NFI, TLI, and CFI $\geq .70$ were considered acceptable (Hair, Black, Babin, Anderson, \& Tatham, 1998).

Medication adherence was measured using three different instruments (30-day medication adherence, dose adherence, and 7-day medication adherence). For the 30-day adherence, the visual analog scale (VAS) was used to measure the overall medication adherence for 30 days. This instrument uses the method of asking the question, "in the past month, how well have you complied with the medication prescribed by your doctor?", In response to this question, the respondents marked their own scores on a continuous scale from 0 to 100 . To measure dose adherence, two questions were asked: "in the past seven days, did you ever not take any of the prescribed medication?" and "in the past seven days, did you ever take your medicine two or more hours later than the prescribed time?"(Tran et al., 2013). The 7-day medication adherence was measured in the same manner as the 30-day medication adherence.

Psychological burden was estimated by measuring stigma, anxiety, and depression. In order to measure the level of stigma in HIV-positive patients, a condensed version of the Internalized AIDS-Related Stigma Scale (IA-RSS) was used (Kalichman, Simbayi, Cloete, Mthembu, Mkhonta, \& Ginindza, 2009). This instrument consisted of six questions with a two-part response given for whether or not the subjects agreed with each sentence of the questions. The sum of scores from each question ranged in total from 0-6 points, where a higher score indicated that the subjects felt a greater level of stigma about HIV infection. This instrument was deemed reliable with a Cronbach's $\alpha$ of .74.

The depression levels of the participants were measured using the Korean version of the Center for Epidemiologic Studies Depression Scale-Revised (K-CESD-R) (Lee et al., 2016). This instrument is designed to measure whether someone has experienced depression in the past week, and it is comprised of 20 questions and is scored on a four-point scale. The sum of scores from each question totaled 0-60 points, where higher scores indicated a higher depression level. The instrument had a good reliability with a Cronbach's $\alpha$ of .93 . Anxiety was measured using the State-Trait Anxiety Inventory (STAI-1) (Spielberger, 1975). This instrument includes a total of 20 questions that are each scored on a four-point scale for a total score range of $20 \sim 80$ points, where higher scores indicated a higher anxiety level. The reliability of the instrument is demonstrated with a Cronbach's $\alpha$ of .87 .

The socioeconomic factors were measured by the subjects' individual economic levels and by their employment status. The subjects were instructed to choose an upper, middle, or lower economic level based on their own 
perceived level, while employment status was measured as dichotomously based on whether or not the subject was currently employed.

Clinical factors were measured by the subjects' overall health status, their experiences with adverse effects from ARV drug, and distress from the HIV symptoms. To measure the health status of the subjects, this study used the question "How you do feel about your health status?" Responses to this health status question were gauged on a five-point scale that ranged from "very good" to "very poor" with higher scores indicating a poorer health status. To measure ARV drug-related adverse effects and distress from HIV symptoms, this study used the lists of the top 20 most frequently-experienced adverse effects of symptoms developed by a medical doctor and a nurse from the hospital's division of infectious diseases. The responses to these adverse effects or symptoms were measured on a five-point Likert scale, with four points for "always" and zero points for "not at all." Based on the sum of all scores, higher scores indicated a higher level of ARV drug-related adverse effects or distress from HIV symptoms.

The health behavioral factor was measured with a self-management. This study used HIV Self-Management Scale (HSMS) by Webel et al. (2012) that was tested on the Korean population by Kim et al. (2015) for validity and reliability. This instrument was comprised of 20 questions in three categories that measured the self-management behavior of HIV-positive patients, and the sum of scores from each question ranged from 0-60 points. Higher scores indicated a higher level of self-management. This instrument can be seen as reliable since it achieved a Cronbach's $\alpha$ of .89 in Kim et al. (2015) and one of .87 in the present study.

\subsection{Ethical Considerations}

The protocols used in this study were approved by the Institutional Review Board at Y University Hospital (IRB No. 4-2013-0673). To align with the recommendation made by the IRB, a verbal consent was received from the subjects instead of a written consent because of the concerns about potential release of personal information. To reward subjects in the study, a monetary gift card worth USD 10 was given to each subject.

\subsection{Data Collection}

Data were collected from HIV-positive patients who had visited the division of infectious diseases at Yeonsei University hospital located in Seoul, South Korea from January 2014 to April 2014. The nurse in the division of infectious diseases screened the candidates based on the inclusion criteria to determine their eligibility for the study. Those who expressed their willingness to participate were taken to a separate room where the researcher provided a thorough explanation on the objectives, procedures, significance, and expected duration of the study. If the candidate gave his or her verbal consent to participate in the study, the survey was conducted. The time required to complete the structured questionnaire was 15-20 minutes.

\subsection{Data Analysis}

To conduct the statistical analyses with the collected data, the IBM SPSS Statistics 24.0 and Amos 24.0 were used. For normality testing on the data, a scatter-plot, skewness analyses, and a univariate Kolmogorov-Smirnov test were used. To calculate the descriptive statistics, frequency, percentage, mean, and standard deviation were estimated. A Cronbach's $\alpha$ was calculated to verify the reliability of the instrument used. Pearson's correlation coefficient was calculated to estimate any multicollinearity or correlations that existed between the measurement variables. In addition, a confirmatory factor analysis (CFA) using maximum likelihood method (MLM) was performed to test the validity of the measurement variables, with the parameters of factor loading $\geq .50$, construct reliability $\geq .70$, and average variance extracted $\geq .50$ estimated in order to ensure convergent validity. To test the research hypotheses and the fitness of the model, structural equation modeling using MLM was performed, with factor loading set to one for a single observed variable. To test the significance of the mediating effects, a bootstrap analysis was performed with a bootstrap sampling setting of 2,000 repetitions (Preacher \& Selig, 2012).

\section{Results}

\subsection{Subjects' Characteristics}

The mean age of the participants was $41.94( \pm 12.72)$ years, with males accounting for $94.7 \%$. For education level, college graduate or higher was the most common with $52.8 \%$. With respect to housing type, living with family was the most common response with $54.9 \%$, while $35.6 \%$ of the participants were living alone. The optimal adherence for the participants as measured by the 30 -day adherence, dose adherence, and 7-day adherence was $46.4 \%, 29.8 \%$, and $50.9 \%$, respectively (Table 1 ). 
Table 1. General Characteristics and Medication Adherence of the Subjects $(N=265)$

\begin{tabular}{lll}
\hline Variables & Categories & $n(\%)$ \\
\hline Age & $\geq 29$ & $51(19.2)$ \\
& $30 \sim 39$ & $74(27.9)$ \\
& $40 \sim 49$ & $71(26.8)$ \\
& $50 \leq$ & $69(26.0)$ \\
\hline Gender & Male & $251(94.7)$ \\
& Female & $14(5.3)$ \\
\hline Marital status & Single & $196(74.0)$ \\
& Married & $50(18.9)$ \\
& Divorced & $10(3.8)$ \\
& Separated & $3(1.1)$ \\
& Bereaved & $6(2.3)$ \\
\hline Education level & $\leq$ High school & $125(47.2)$ \\
& $\geq$ College or more & $140(52.8)$ \\
\hline Dwelling* & Solitary & $94(35.6)$ \\
& With family & $145(54.9)$ \\
& With friend or partner & $25(9.5)$ \\
\hline Optimal adherence of HAART & 30-day adherence & $123(46.4)$ \\
& Dose adherence & $79(29.8)$ \\
& 7-day adherence & $135(50.9)$ \\
\hline
\end{tabular}

Note. HAART=highly active antiretroviral therapy.

$*_{N}=264$.

\subsection{Descriptive Statistics and Correlations of Measurement Variables}

The descriptive statistics of the measurement variables are shown in Table 2. As illustrated in Table 2, the medication adherence level was highest when measured by the 30-day adherence, with an average of 90.05 , and this level was lowest when measured by dose adherence, with an average of 54.15. The values for skewness and kurtosis in the distribution of the measurement variables did not exceed 2 and 7, respectively, which suggests that the instruments used in the analysis satisfied the normal distribution assumption that was required to apply the structural equation model. However the Mardia's test for multivariate normality showed that normality was not satisfied at a significance level of $.05(p=.002)$. Nonetheless, even if the multivariate normality assumption is not satisfied, the parameters estimated with MLM are reported to be reliable (Kline, 2011), and consequently this analysis used MLM, instead of the generalized least square method, to test the model. An analysis of the correlations between the measurement variables showed that the correlation coefficients were all $<.8$, which confirmed that there was no multicollinearity.

Table 2. Descriptive Statistics of the Observed Variables $(N=265)$

\begin{tabular}{lllll}
\hline Latent variables & Measured variables & $M(S D)$ & Skewness & Kurtosis \\
\hline Socioeconomic factors & Perceived economic status & $1.65(0.58)$ & 0.23 & -0.69 \\
& Employment status & $0.69(0.46)$ & -0.85 & -1.29 \\
\hline Clinical factors & Health status & $2.65(0.97)$ & -0.05 & -0.51 \\
& Adverse effect & $43.14(12.94)$ & 0.60 & -0.33 \\
& Symptom distress & $29.75(9.64)$ & 1.29 & 1.88 \\
\hline
\end{tabular}




\begin{tabular}{lllll}
\hline Psychological burden & Stigma & $4.00(1.66)$ & -0.23 & -1.11 \\
& Depression & $17.96(11.70)$ & 0.85 & 0.71 \\
& Anxiety & $47.88(11.85)$ & -0.19 & -0.22 \\
\hline Self-management & & $37.90(9.65)$ & -0.11 & 0.24 \\
\hline Medication adherence & 30-day adherence & $90.05(10.24)$ & -1.22 & 1.47 \\
& Dose adherence & $54.15(35.65)$ & -0.12 & -1.02 \\
& 7-day adherence & $83.21(19.73)$ & -0.89 & -.10 \\
\hline Multivariate & & & & 8.11 \\
\hline
\end{tabular}

\subsection{Tests of Fitness and Effects on Structural Equation Model}

An assessment of the model's fit showed that the model was within the optimal range with a parsimonious fit index of $\chi^{2}$ /df equal to 2.65 (lower than the maximum of 3), the RMSEA equal to .079 (lower than the maximum of .08), and the GFI equal to .93 (higher than the minimum of .90) (Hair et al., 1998). With respect to the incremental fit index, the CFI (.93) was within the optimal range with .93, while the NFI (.89) and the TLI (.89) were within the acceptable range (higher than the minimum of .90). Consequently, it was determined that was suitable.

An analysis on the effects of the independent variables in the model showed that five direct pathways out of 10 pathways were significant (Figure 2), and the variable that had a significant direct effect on medication adherence was self-management $(\beta=.31, p=.002)$ and explained $14.7 \%$ of the variance of medication adherence. With respect to self-management, the psychological burden showed a significant direct effect $(\beta=-.49, p=.002)$, and explained $30.8 \%$ of variance of self-management. With respect to psychological burden, socioeconomic $(\beta=-.46$, $p=.001)$ and clinical $(\beta=.47, p=.001)$ factors showed a significant direct effect, and explained $62.1 \%$ of variance of psychological burden. With respect to clinical factors, socioeconomic factors showed a significant direct effect $(\beta=-.44, p=.001)$ and explained $19.1 \%$ of variance of clinical factors (Table 3 ).

The psychological burden did not show a significant direct effect on medication adherence $(\beta=-.11, p=.573)$, but its indirect effect mediated through self-management was significant $(\beta=-.15, p=.002)$, and it can therefore be inferred that self-management had a full mediating effect on the path through which psychological burden affected medication adherence (Table 3).

Table 3. Effects of Predictive Variables on Endogenous Variables in the Model $(N=265)$

\begin{tabular}{|c|c|c|c|c|c|c|c|}
\hline $\begin{array}{l}\text { Endogenous } \\
\text { variable }\end{array}$ & $\begin{array}{l}\text { Explanatory } \\
\text { variable }\end{array}$ & $\begin{array}{l}\text { Standardized } \\
\text { estimate }\end{array}$ & C.R. & $\mathrm{SMC}$ & $\begin{array}{l}\text { Standardized } \\
\text { direct } \\
\operatorname{effect}(p)^{*}\end{array}$ & $\begin{array}{l}\text { Standardized } \\
\text { indirect } \\
\operatorname{effect}(p)^{*}\end{array}$ & $\begin{array}{l}\text { Standardized } \\
\text { total effect }(p)^{*}\end{array}$ \\
\hline \multirow[t]{4}{*}{$\begin{array}{l}\text { Medication } \\
\text { Adherence }\end{array}$} & $\begin{array}{l}\text { Socioeconomic } \\
\text { factors }\end{array}$ & -.16 & -1.06 & .15 & $-.16(.375)$ & $.22(.022)$ & $.06(.620)$ \\
\hline & Clinical factors & -.09 & -0.84 & & $-.09(.489)$ & $-.16(.082)$ & $-.25(.015)$ \\
\hline & $\begin{array}{l}\text { Psychological } \\
\text { burden }\end{array}$ & -.11 & -0.62 & & $-.11(.573)$ & $-.15(.002)$ & $-.26(.189)$ \\
\hline & Self-management & .31 & 3.68 & & $.31(.002)$ & 0 & $.31(.002)$ \\
\hline \multirow[t]{3}{*}{ Self-management } & $\begin{array}{l}\text { Socioeconomic } \\
\text { factors }\end{array}$ & -.02 & -0.19 & .31 & $-.02(.915)$ & $.37(.001)$ & $.35(.001)$ \\
\hline & Clinical factors & -.11 & -1.14 & & $-.11(.283)$ & $-.23(.002)$ & $-.34(.001)$ \\
\hline & $\begin{array}{l}\text { Psychological } \\
\text { burden }\end{array}$ & -.49 & -3.41 & & $-.49(.002)$ & 0 & $-.49(.002)$ \\
\hline
\end{tabular}




\begin{tabular}{|c|c|c|c|c|c|c|c|}
\hline \multirow[t]{2}{*}{$\begin{array}{l}\text { Psychological } \\
\text { burden }\end{array}$} & $\begin{array}{l}\text { Socioeconomic } \\
\text { factors }\end{array}$ & -.46 & -3.71 & .62 & $-.46(.001)$ & $-.21(<.001)$ & $-.66(.001)$ \\
\hline & Clinical factors & .47 & 4.07 & & $.47(.001)$ & 0 & $.47(.001)$ \\
\hline Clinical factor & $\begin{array}{l}\text { Socioeconomic } \\
\text { factors }\end{array}$ & -.44 & -3.40 & .19 & $-.44(.001)$ & 0 & $-.44(.001)$ \\
\hline
\end{tabular}

Note. $\mathrm{SE}=$ Standard Error, $\mathrm{CR}=$ Critical Ratio, $\mathrm{SMC}=$ Squared Multiple Correlation $\left(\mathrm{R}^{2}\right)$

*p-value of Bootstrapping Analysis

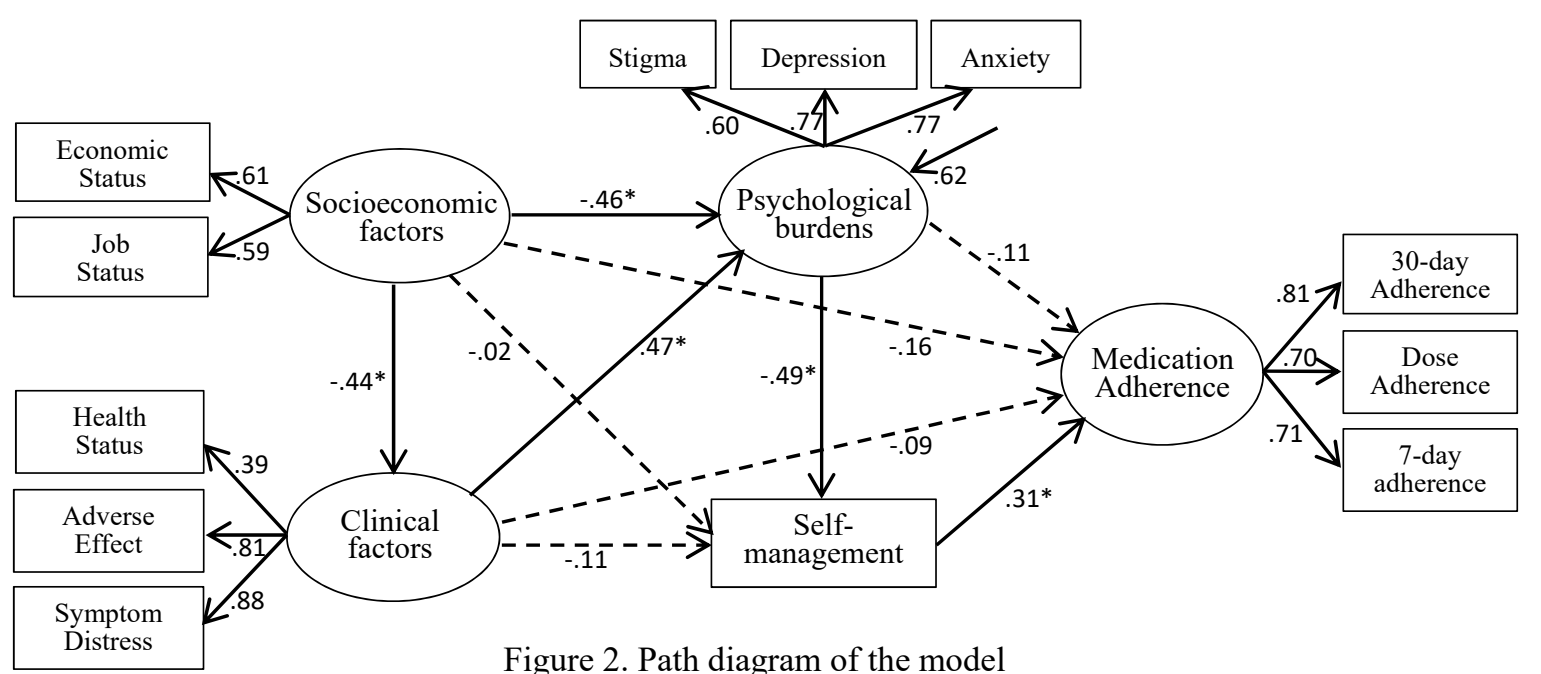

\section{Discussion}

The objective of this study was to identify the factors that influence medication adherence in Korean patients with HIV, as well as to investigate the paths by which the psychological burden affects medication adherence when various factors are also comprehensively considered. The findings showed that self-management had a direct effect on medication adherence. The psychological burden variable did not have a significant direct effect on medication adherence, but it did have a significant indirect effect on medication adherence mediated by self-management. These findings present evidence for the path through which the psychological burden affects medication adherence, which had not yet been identified in previous research. The results also suggest that the psychological burden is a determining factor of medication adherence.

When a patient does not fully adhere to HAART, this can not only exacerbate the disease, but it can also have a negative effect on the patients' quality of life due to the lost opportunity of transitioning to a long-term healthy life pattern (Park et al., 2014). Patients with HIV have higher prevalence of mental illness, most often depression and anxiety, than dose the general population with otherwise similar demographics (Nel \& Kagee, 2013). Depression and anxiety represent the typical psychological burden that interferes with medication adherence in patients with HIV (Park et al., 2014). Depression has been recognized as a determining factor that diminishes medication adherence, quality of life, and treatment outcome (Nanni et al., 2015). Anxiety independently has a negative effect on medication adherence when the effects of other psychosocial factors are controlled (Schönnesson et al., 2007).

The stigma faced by patients with HIV can cause depression or anxiety, and it also has a negative effect on medication adherence by reducing a patient's functioning because of lowered self-esteem, less social support (Berger, Ferrans \& Lashley, 2001), and interference with the health behaviors (Clark, Lindner, Armistead \& Austin, 2004). However, the findings in this study showed that the psychological burden did not have a significant direct effect on medication adherence. The reason for this is probably because both psychological burden and self-management were both included in the model to explain medication adherence. Depression can lower the self-efficacy for medication adherence (Dworkin, Chakraborty, Zychowski, Donenberg, Novak, \& Garofalo, 2018; Reynolds et al., 2004) or increase the negative attitude towards HIV drugs to directly undermine treatment adherence (Malow et al., 2013). Moreover, the feeling of hopelessness caused by depression can have an indirect effect on medication adherence by disrupting a regular pattern of healthy behaviors that should be sustained for a 
long time (Park et al., 2014).

In addition, anxiety lowers the ability to concentrate, which interferes with adherence to the accurate time and dosage medication requirements (Nel \& Kagee, 2013), and also negatively affects a patient's monitoring of their symptoms and actually visiting their care providers. These are examples of HIV self-management behaviors (Swendeman, Ingram \& Roteram-Borus, 2009), and, therefore, when psychological burden and self-management are considered simultaneously, the significance of the indirect effect of the psychological burden mediated by self-management was more prominent than the direct effect of the psychological burden on medication adherence.

Self-management is a variable that has a positive effect on improving HIV treatment adherence and following long-term treatment programs (Saberi \& Johnson, 2011). This is consistent with the finding in this study that the self-management variable had a direct effect on medication adherence. In addition, in increase in self-management can cause changes to the mental health and lifestyle patterns of the patients that can subsequently lead to improved HIV treatment outcomes, such as an improved CD4+ or a reduced virus titer, while also improving the quality of life of the patients (Holtz, Sowell, Vanbrachle, Velasquez, \& Hernandez-Alonso, 2014). Therefore, an intervention approach that focuses on patients' psychological burdens and self-management ability should effectively improve medication adherence in patients with HIV.

The clinical factors did not have either a significant direct effect or indirect effect on medication adherence. This was consistent with the study by Godin et al. (2005), which reported that ARV drug-related adverse effects are not predictive of treatment adherence. However, these results contradict a systematic literature review by Wasti et al. (2012), which reported that ARV drug-related adverse effects are the major cause of non-compliance to HAART, and a study by Roca et al. (2000), which claimed that the most common reason for discontinuing HAART was the ARV drug-related adverse effects. Numerous studies have reported that patients with HIV often experience symptoms from taking ARV drugs, such as nausea, visual impairment, loss of appetite, and insomnia, which can have a negative effect on treatment adherence (Isa, Abubakar, \& Chedi, 2018; Mendes et al., 2018; Roca, Gomez, $\&$ Arnedo, 2000). On the other hand, some recent studies have suggested that ARV drug-related adverse effects do not present major barriers to medication adherence (Azia, Mukumbang, \& Van Wyk, 2016). This ambivalence about the relationship between ARV drug-related adverse effects and medication adherence might be due to the varying duration of the patients' treatments or the use of complementary medicine that is sometimes given to reduce discomfort (Wasti et al., 2012). Moreover, the connection between medication adherence and ARV drug-related adverse effects is moderated by the socioeconomic status of the patients' resident countries (Li et al., 2017). Given this information, it is necessary to conduct future studies that consider multinational subjects with different socioeconomic levels to investigate the moderating effects of socioeconomic factors in the relationship between ARV drug-related adverse effects and medication adherence.

The level of HIV-related symptoms indicates the severity of the HIV disease, and the burden from these related symptoms can interfere with adhering to medication plans (Gay et al., 2011). However, clinical factors did not have a significant direct effect on medication adherence in this study. When HIV-related symptoms are severe, they can interfere with medication adherence behavior; at the same time, the burden of HIV symptoms might cause the patient perceive that the severity of the disease is higher. Therefore, the possibility that this might cause the patient to more actively follow the treatment plan cannot be ignored. This corresponds to the perceived threat in the health belief model (Park et al., 2014), which explains that perceived threats can act as a motivation for continuing the healthy behavior; for the present study, this health belief model might explain the observed direct effect of the clinical factors on influencing self-management. These results are consistent with the results on Asian HIV-positive as reported by Park et al. (2014).

Socio-demographic factors, such as economic status and education level, are known to have an effect on practicing healthy behaviors (Atella, \& Kopinska, 2014). However, in this study, the socioeconomic factors did not have a significant effect on medication adherence. A systematic review of the literature shows that only half of the existing studies reported a significant association between socioeconomic factors and medication adherence (Falagas, Zarkadoulia, Pliatsika, \& Panos, 2008), and these results differed based on the patients' countries. In regions with limited economic resources, economic factors interfered with medication adherence (Boyer et al., 2011); however, in a study that explored American patients with HIV, there were no significant associations between economic factors and medication adherence (Sayles et al., 2009). In Korea, since the government pays the treatment costs, patients' economic levels aware not directly associated with treatment adherence. However, demographic factors did have a significant direct effect on the psychological burden, while these factors also had an indirect effect on self-management mediated by the psychological burden. Therefore, the potential for demographic factors to influence treatment adherence cannot be overlooked. Despite the fact that patients with 
HIV belong to a population group who desperately need health management and health-promoting practices, they lack the supportive environmental resources to have opportunities for screening abnormal conditions. Also, since patients with HIV often have low-income levels or low education levels, they might face difficulties in practicing and sustaining healthy behaviors (Park et al., 2014). Therefore, it is still necessary to improve the economic conditions of patients with HIV.

The present study found that the optimal adherence level for HAART by Korean patients with HIV was $46.4 \%$. According to previous studies that reported on HAART adherence, the optimal adherence in the US or Europe was $60-70 \%$ (Saberi \& Johnson, 2011), whereas in Africa, where HIV prevalence is very high, adherence was higher than $80 \%$ (Mills et al., 2006). In comparison to these figures, adherence in other Asian countries was relatively higher at $85 \%$, but the possibility of overestimation due to measurement errors cannot be dismissed (Tran et al., 2013). Until now, there has been only one study that investigated HAART adherence levels in Korean patients with HIV (Choi et al., 2005), which means that there is not yet enough data to identify valid information on treatment adherence levels in Korean patients. According Choi et al. (2005), only $46.9 \%$ of the subjects responded that they took all of the medication that was prescribed for one week, while a mere $10.2 \%$ of the subjects had reported that they did not take their medication as prescribed on 10 or more occasions; therefore it can be assumed that treatment adherence is low among Korean patients with HIV. This suggests that it is important, from a clinical and public health perspective, to precisely identify the factors of medication adherence in Korean patients with HIV to minimize the social costs from an HIV infection and to expand HIV treatment.

\section{Conclusions}

The present study aimed to identify the level of medication adherence in Korean patients with HIV, as well as to identify the path through which the patients' psychological burdens had an effect on medication adherence. The study also aimed to use the findings to shed a light on negative health outcomes in Korean patients with HIV who suffer from psychological burdens and to establish a foundation for creating policies and developing interventions to promote medication adherence. The results indicate that medication adherence in Korean patients with HIV was lower than that of patients in the US, Europe, and other Asian countries. This highlights the realistic context in Korea, which requires active intervention for improving medication adherence. To support this, future studies need to identify medication adherence levels through highly representative samples of the Korean HIV-positive population.

Given that the psychological burden has been identified as a factor of medication adherence in Korean patients with HIV, it is necessary to screen for this psychological burden during the initial stage of diagnosis in order to improve the health of patients with HIV and to identify population groups at risk through continued monitoring. Also, it is important to develop intervention program that focus on psychological support and self-management.

\section{Acknowledgements}

This study was conducted with advice from Dr. Jung-Yeul Lee, a retired professor, college of Nursing, Yeonsei University, and Joon-Yong Choi, a medical doctor at the division of infectious diseases at Yeonsei University Hospital, during the planning and data collection stages. This study was supported by the research foundation of Wonkwang University, 2018.

\section{Competing Interests Statement}

The author declares that there are no competing or potential conflicts of interest.

\section{References}

Atella, V., \& Kopinska, J. (2014). Body weight, eating patterns, and physical activity: The role of education. Demography, 51(4), 1225-1249. https://doi.org/10.1007/s13524-014-0311-z

Azia, I. N., Mukumbang, F. C., \& Van Wyk, B. (2016). Barriers to adherence to antiretroviral treatment in a regional hospital in Vredenburg, Western Cape, South Africa. Southern African Journal of HIV Medicine, 17(1). https://doi.org/10.4102/sajhivmed.v17i1.476. eCollection 2016.

Berger, B. E., Ferrans, C. E., \& Lashley, F. R. (2001). Measuring stigma in people with HIV: psychometric assessment of the HIV stigma scale. Research in Nursing \& Health, 24(6), 518-529.

Boyer, S., Clerc, I., Bonono, C. R., Marcellin, F., Bile, P. C., \& Ventelou, B. (2011). Non-adherence to antiretroviral treatment and unplanned treatment interruption among people living with HIV/AIDS in Cameroon: Individual and healthcare supply-related factors. Social Science \& Medicine, 72(8), 1383-1392. https://doi.org/10.1016/j.socscimed.2011.02.030 
Choi, J. Y., Park, Y. S., Kim, C. O., Park, Y. S., Yoon, H. J., Shin, S. Y., ... Kim, J. M. (2005). Correlation between Adherence to Antiretroviral Treatment and Virologic Failure in HIV-infected Koreans. Infection and Chemotherapy, 37(1), 9-15.

Clark, H. J., Lindner, G., Armistead, L., \& Austin, B. J. (2004). Stigma, disclosure, and psychological functioning among HIV-infected and non-infected African-American women. Women Health, 38(4), 57-71. https://www.ncbi.nlm.nih.gov/pubmed/14750776

Cohen, M. S., Chen, Y. Q., McCauley, M., Gamble, T., Hosseinipour, M. C., Kumarasamy, ... Fleming, T. R. (2011). Prevention of HIV-1 infection with early antiretroviral therapy. New England Journal of Medicine, 365(6), 493-505. https://doi.org/10.1056/NEJMoa1105243

Dalal, R. P., MacPhail, C., Mqhayi, M., Wing, J., Feldman, C., Chersich, M. F., \& Venter, W. D. (2008). Characteristics and outcomes of adult patients lost to follow-up at an antiretroviral treatment clinic in Johannesburg, South Africa. Journal of Acquired Immune Deficiency Syndromes, 47(1), 101-107. https://doi.org/10.1097/QAI.0b013e31815b833a

Dworkin, M. S., Chakraborty, A., Zychowski, D., Donenberg, G., Novak, R., \& Garofalo, R. (2018). Self-efficacy and ability to read as factors associated with antiretroviral therapy adherence in an HIV-infected population. International journal of STD \& AIDS, https://doi.org/10.1177/0956462418776073

Falagas, M. E., Zarkadoulia, E. A., Pliatsika, P. A., \& Panos, G. (2008). Socioeconomic status (SES) as a determinant of adherence to treatment in HIV infected patients: a systematic review of the literature. Retrovirology, 5(1), 13. https://www.ncbi.nlm.nih.gov/pubmed/18241330

Gari, S., Doig-Acuña, C., Smail, T., Malungo, J. R., Martin-Hilber, A., \& Merten, S. (2013). Access to HIV/AIDS care: a systematic review of socio-cultural determinants in low and high income countries. BMC Health Service Research, 13(1), 198. https://doi.org/10.1186/1472-6963-13-198.

Gay, C., Portillo, C. J., Kelly, R., Coggins, T., Davis, H., Aouizerat, B. E., ... Lee, K. A. (2011). Self-reported medication adherence and symptom experience in adults with HIV. The Journal of the Association of Nurses in Aids Care : JANAC, 22(4), 257-268. https://doi.org/10.1016/j.jana.2010.11.004

Gibson, R. C., Neita, S. M., Abel, W. D., James, K., \& Eldemire-Shearer, D. (2013). Sociodemographic factors associated with depressive symptoms among elderly persons from two communities in Kingston, Jamaica. West Indian Medical Journal, 62(7), 615-619. https://www.ncbi.nlm.nih.gov/pubmed/24831899

Godin, G., Cote, J., Naccache, H., Lambert, L. D., \& Trottier, S. (2005). Prediction of adherence to antiretroviral therapy: a one-year longitudinal study. AIDS care, 17(4), 493-504. https://www.ncbi.nlm.nih.gov/pubmed/16036235

Gonzalez, J. S., Batchelder, A. W., Psaros, C., \& Safren, S. A. (2011). Depression and HIV/AIDS treatment nonadherence: a review and meta-analysis. Journal of Acquired Immune Deficiency Syndromes, 58(2). https://doi.org/10.1097/QAI.0b013e31822d490a.

Kline, R. (2011). Principles and Practice of Structural Equation Modeling, 3rd edn Guilford Press. New York.

Holtz, C., Sowell, R., VanBrackle, L., Velasquez, G., \& Hernandez-Alonso, V. (2014). A quantitative study of factors influencing quality of life in rural Mexican women diagnosed with HIV. Journal of the Association of Nurses in AIDS Care, 25(6), 555-567. https://doi.org/10.1016/j.jana.2014.03.002

Isa, A. M., Abubakar, I. J., \& Chedi, B. A. (2018). Adverse drug reactions to antiretroviral drugs and impact on treatment adherence among HIV patients in northwestern Nigeria. Drugs \& Therapy Perspectives, 1-8.

Kabore, I., Bloem, J., Etheredge, G., Obiero, W., Wanless, S., Doykos, P., ... Tiam, A. (2010). The effect of community-based support services on clinical efficacy and health-related quality of life in HIV/AIDS patients in resource-limited settings in sub-Saharan Africa. AIDS Patient Care and STDS, 24(9), 581-594. https://doi.org/10.1089/apc.2009.0307

Kalichman, S. C., Simbayi, L. C., Cloete, A., Mthembu, P. P., Mkhonta, R. N., \& Ginindza, T. (2009). Measuring AIDS stigmas in people living with HIV/AIDS: the Internalized AIDS-Related Stigma Scale. AIDS care, 21(1), 87-93. https://doi.org/10.1080/09540120802032627

Kim, G. S., Chu, S. H., Park, Y., Choi, J. Y., Lee, J. I., Park, C. G., \& McCreary, L. L. (2015). Psychometric Properties of the Korean version of the HIV self-management scale in patients with HIV. Journal of Korean Academy of Nursing, 45(3), 439-448. https://doi.org/10.4040/jkan.2015.45.3.439 
Kim, K. H. (2005). The Relation Among Fit Indexes, Power, and Sample Size in Structural Equation Modeling. Structural Equation Modeling, 12, 368-390. https://doi.org/10.1207/s15328007sem1203_2

Lee, S., Oh, S. T., Ryu, S. Y., Jun, J. Y., Lee, K., Lee, E., ... Choi, W. J. (2016). Validation of the Korean version of Center for Epidemiologic Studies Depression Scale-Revised (K-CESD-R). Korean Journal of Psychosomatic Medicine, 24(1), 83-93.

Li, H., Marley, G., Ma, W., Wei, C., Lackey, M., Ma, Q., ... Tucker, J. D. (2017). The role of ARV associated adverse drug reactions in influencing adherence among HIV-infected individuals: a systematic review and qualitative meta-synthesis. AIDS and Behavior, 21(2), 341-351. https://doi.org/10.1007/s10461-016-1545-0

Lima, V. D., Harrigan, R., Murray, M., Moore, D. M., Wood, E., Hogg, R. S., \& Montaner, J. S. (2008). Differential impact of adherence on long-term treatment response among naive HIV-infected individuals. AIDS, 22(17), 2371-2380. https://doi.org/10.1097/QAD.0b013e328315cdd3

Malow, R., Devieux, J. G., Stein, J. A., Rosenberg, R., Jean-Gilles, M., Attonito, J., ... Pape, J. W. (2013). Depression, substance abuse and other contextual predictors of adherence to antiretroviral therapy (ART) among Haitians. AIDS and Behavior, 17(4), 1221-1230. https://doi.org/10.1007/s10461-012-0400-1

Mendes, J. C., de Fátima Bonolo, P., Ceccato, M. D. G. B., de Oliveira Costa, J., Reis, A. M. M., dos Santos, H., \& Silveira, M. R. (2018). Adverse reactions associated with first-line regimens in patient initiating antiretroviral therapy. European journal of clinical pharmacology, 1-12. https://doi.org/10.1007/s00228-018-2472-y

Mills, E. J., \& Ford, N. (2012). Home-based HIV counseling and testing as a gateway to earlier initiation of antiretroviral therapy. Clinical Infectious Diseases, 54(2), 282-284. https://doi.org/10.1093/cid/cir812

Mills, E. J., Nachega, J. B., Buchan, I., Orbinski, J., Attaran, A., Singh, S., ... Wilson, K. (2006). Adherence to antiretroviral therapy in sub-Saharan Africa and North America: a meta-analysis. Jama, 296(6), 679-690. https://doi.org/10.1001/jama.296.6.679

Murray, L. K., Semrau, K., McCurley, E., Thea, D. M., Scott, N., Mwiya, M., ... Bolton, P. (2009). Barriers to acceptance and adherence of antiretroviral therapy in urban Zambian women: a qualitative study. AIDS Care, 2l(1), 78-86. https://doi.org/10.1080/09540120802032643

Nanni, M. G., Caruso, R., Mitchell, A. J., Meggiolaro, E., \& Grassi, L. (2015). Depression in HIV infected patients: a review. Current Psychiatry Reports, 17(1), 530. https://doi.org/10.1007/s11920-014-0530-4.

Nel, A., \& Kagee, A. (2013). The relationship between depression, anxiety and medication adherence among patients receiving antiretroviral treatment in South Africa. AIDS Care, 25(8), 948-955. https://doi.org/10.1080/09540121.2012.748867

Park, Y., Seo, M. J., Kim, S., \& Park, S. Y. (2014). Experience of Treatment Adherence in Korean Patients with HIV. Journal of Korean Academy of Nursing, 44(4). https://doi.org/10.4040/jkan.2014.44.4.407.

Parker, R. A., Rabideau, D. J., Sax, P. E., Tierney, C., Daar, E. S., Collier, A. C., ... Freedberg, K. A. (2017). Impact of Medication Adherence on Virologic Failure in A5202: A Randomized, Partially Blinded, Phase 3B Study. Clinical Infectious Diseases, 64(11), 1612-1614. https://doi.org/10.1093/cid/cix176.

Preacher, K. J., \& Selig, J. P. (2012). Advantages of Monte Carlo confidence intervals for indirect effects. Communication Methods and Measures, 6(2), 77-98. https://doi.org/10.1080/19312458.2012.679848

Reynolds, N. R., Testa, M. A., Marc, L. G., Chesney, M. A., Neidig, J. L., Smith, S. R., ... Robbins, G. K. (2004). Factors influencing medication adherence beliefs and self-efficacy in persons naive to antiretroviral therapy: a multicenter, cross-sectional study. AIDS and Behavior, 8(2), 141-150. https://doi.org/10.1023/B:AIBE.0000030245.52406.bb

Roca, B., Gomez, C. J., \& Arnedo, A. (2000). Adherence, side effects and efficacy of stavudine plus lamivudine plus nelfinavir in treatment-experienced HIV-infected patients. Journal of infection, 41(1), 50-54. https://doi.org/10.1053/jinf.2000.0678

Saberi, P., \& Johnson, M. O. (2011). Technology-based self-management methods of improving antiretroviral adherence: a systematic review. PLoS One, 6(11), e27533. https://doi.org/10.1371/journal.pone.0027533

Sayles, J. N., Wong, M. D., Kinsler, J. J., Martins, D., \& Cunningham, W. E. (2009). The association of stigma with self-management reported access to medical care and antiretroviral therapy adherence in persons living with HIV/AIDS. Journal of General Internal Medicine, 24(10), 1101-1108. https://doi.org/10.1007/s11606-009-1068-8 
Schönnesson, L. N., Williams, M. L., Ross, M. W., Bratt, G., \& Keel, B. (2007). Factors associated with suboptimal antiretroviral therapy adherence to dose, schedule, and dietary instructions. AIDS and Behavior, 11(2), 175-183. https://doi.org/10.1007/s10461-006-9160-0

Spielberger, C. D. (1975). Anxiety: State-Trait Process. Stress and Anxiety. New York: John Willy and Sons Inc., 115-143.

Swendeman, D., Ingram, B. L., \& Rotheram-Borus, M. J. (2009). Common elements in self-management of HIV and other chronic illnesses: an integrative framework. AIDS Care, 21(10), 1321-1334. https://doi.org/10.1080/09540120902803158

Tran, B. X., Nguyen, L. T., Nguyen, N. H., Hoang, Q. V., \& Hwang, J. (2013). Determinants of antiretroviral treatment adherence among HIV/AIDS patients: a multisite study. Global Health Action, 6, 19570. https://doi.org/10.3402/gha.v6i0.19570

van Luenen, S., Garnefski, N., Spinhoven, P., Spaan, P., Dusseldorp, E., \& Kraaij, V. (2018). The benefits of psychosocial interventions for mental health in people living with HIV: a systematic review and meta-analysis. AIDS and Behavior, 22(1), 9-42. https://doi.org/10.1007/s10461-017-1757-y

Wasti, S. P., Simkhada, P., Randall, J., Freeman, J. V., \& van Teijlingen, E. (2012). Factors influencing adherence to antiretroviral treatment in Nepal: a mixed-methods study. PLoS One, 7(5), e35547. https://doi.org/10.1371/journal.pone.0035547

Webel, A. R., Asher, A., Cuca, Y., Okonsky, J. G., Kaihura, A., Rose, C. D., ... \& Salata, R. A. (2012). Measuring HIV self-management in women living with HIV/AIDS: A psychometric evaluation study of the HIV Self-management Scale. Journal of acquired immune deficiency syndromes (1999), 60(3), e72. https://doi.org/10.1097/QAI.0b013e318256623d

\section{Copyrights}

Copyright for this article is retained by the author(s), with first publication rights granted to the journal.

This is an open-access article distributed under the terms and conditions of the Creative Commons Attribution license (http://creativecommons.org/licenses/by/4.0/). 